\title{
Ghrelin O-acyltransferase (GOAT) and energy metabolism
}

\author{
Ziru Li ${ }^{1}$, Michael Mulholland ${ }^{1 *} \&$ Weizhen Zhang ${ }^{1,2 *}$ \\ ${ }^{1}$ Department of Surgery, University of Michigan Medical Center, Ann Arbor MI 48109-0346, USA, \\ ${ }^{2}$ Department of Physiology and Pathophysiology, Peking University Health Science Center, Beijing 100191, China
}

Received August 17, 2015; received October 9, 2015; published online January 4, 2016

\begin{abstract}
Ghrelin O-acyltransferase (GOAT), a member of MBOATs family, is essential for octanoylation of ghrelin, which is required for active ghrelin to bind with and activate its receptor. GOAT is expressed mainly in the stomach, pancreas and hypothalamus. Levels of GOAT are altered by energy status. GOAT contains 11 transmembrane helices and one reentrant loop. Its invariant residue His-338 and conserved Asn-307 are located in the endoplasmic reticulum lumen and cytosol respectively. GOAT contributes to the regulation of food intake and energy expenditure, as well as glucose and lipids homeostasis. Deletion of GOAT blocks the acylation of ghrelin leading to subsequent impairment in energy homeostasis and survival when mice are challenged with high energy diet or severe caloric restriction. GO-CoA-Tat, a peptide GOAT inhibitor, attenuates acyl-ghrelin production and prevents weight gain induced by a medium-chain triglycerides-rich high fat diet. Further, GO-CoA-Tat increases glucose-induced insulin secretion. Overall, inhibition of GOAT is a novel strategy for treatment of obesity and related metabolic disorders.
\end{abstract}

ghrelin O-acyltransferase (GOAT), acyl-ghrelin, enzyme inhibitor, food intake, energy metabolism, obesity

Citation: $\quad$ Li, Z., Mulholland, M., and Zhang, W. (2016). Ghrelin O-acyltransferase (GOAT) and energy metabolism. Sci China Life Sci 59, 281-291. doi: $10.1007 / \mathrm{s} 11427-015-4973-6$

\section{INTRODUCTION}

Ghrelin is the only circulating hormone that exhibits potent stimulation of food intake. This property of ghrelin has made it the focus of studies which explore the molecular mechanisms of energy metabolism with the hope of developing novel therapeutic strategy for obesity and related metabolic diseases. The active form of ghrelin contains a unique octanoylation site. Search for the octanoylation catalytic enzyme led to the discovery of ghrelin O-acyltransferase (GOAT). GOAT is the unique enzyme responsible for ghrelin acylation, enabling active ghrelin to bind with its receptor, growth hormone secretagogue receptor 1a (GHSR1a). Acyl-ghrelin promotes a positive energy balance by increasing food intake and reducing energy expenditure, therefore leading to an increase in body weight and adipos-

*Corresponding author (email: weizhenz@umich.edu; micham@umich.edu) ity. Further, acyl-ghrelin affects glucose metabolism.

Ghrelin and its receptor have been targets for therapeutic agents against obesity, and more than 20 drugs have targeted the ghrelin/GHSR1a system. While ghrelin antagonists initially held promise, long term efficacy has been disappointing. Alternative approaches targeting GOAT are appealing. Evidence is emerging that inhibition of active ghrelin production by manipulating GOAT may provide a novel strategy for treatment of obesity. This chapter provides a review of GOAT, its tissue distribution and regulation, enzyme characteristics, effects of the GOAT/ghrelin system on energy metabolism, and the effects of interference of GOAT with physiological functions.

\section{DISCOVERY OF GHRELIN O-ACYLTRANSFERASE (GOAT)}

In 1984, Bowers et al. (Bowers et al., 1984) identified a 
synthetic hexapeptide, His-D-Trp-Ala-Trp-D-Phe-Lys- $\mathrm{NH}_{2}$ (GHRP-6), as a potent stimulator for growth hormone release in vitro and in vivo by an unknown mechanism distinct from growth hormone release hormone and somatostatin pathways. This observation indicated the presence of a unique receptor. As a peptide, GHRP-6 did not readily lend itself to optimization of pharmacokinetic properties by medicinal chemistry. Subsequently, Bowers and other scientists developed various synthetic peptidyl and nonpeptidyl molecules named growth hormone secretagogue (GHS) (Smith et al., 2004). In 1996, GHSs receptor was identified in porcine and rat anterior pituitary membranes as a G-protein-coupled receptor (Howard et al., 1996). Cell lines stably expressing the GHS-R were used for identification of endogenous GHS-R ligands. In 1999, Kojima et al. (Kojima et al., 1999) screened several tissue extracts and isolated the endogenous nature ligand for GHS-R from gastric extracts and named it ghrelin. The ghrelin amino acid sequence in rat was determined as GSSFLSPEHQKAQQRKESKKPPA KLQPR in which serine-3 (Ser3) is n-octanoylated. Octanoylation is necessary for binding and for activation of the GHS-R. The details of acylation and the enzyme that facilitates this modification remained elusive.

In 2008, the enzyme responsible for ghrelin octanoylation was identified independently by two research groups. Yang et al. (Yang et al., 2008a) provide the first evidence for ghrelin O-acyltransferase (GOAT). They determined the portion of the mouse genome encoding 16 membrane-bound O-acyl transferase (MBOAT) protein sequences. These investigators revealed that one of these MBOATs catalyzed the octanoylation of ghrelin by co-transfecting endocrine cells lines with ghrelin and MBOAT constructs. This MBOAT facilitating ghrelin acylation was then named ghrelin O-acyl transferase (GOAT) (Yang et al., 2008a). A series of transfection experiments on mouse pituitary AtT-20 cells, rat insulinoma INS-1 cells, and mouse insulinoma MIN-6 cells validated GOATdependent octanoylation of ghrelin in these rodent endocrine cell lines. Mutation of the serine at position 3 to alanine prevented the acyl modification of ghrelin by GOAT, indicating that the presence of the third serine is essential for GOAT-dependent octanoylation of ghrelin (Yang et al., 2008a). The studies demonstrated that proghrelin is octanoylated before reaching the Golgi where prohormone convertase 1/3 (PC 1/3) posttranslationally cleaves proghrelin to form mature ghrelin (Zhu et al., 2006). These studies suggest that GOAT is present in the endoplasmic reticulum and catalyzes the acylation on proghrelin before being translocated to the Golgi.

At the same time, Gutierrez et al. (Gutierrez et al., 2008) reported that a member of the MBOAT family is involved in ghrelin acylation in human medullary thyroid carcinoma (TT) cells. Silencing the GOAT gene by its specific siRNA, rather than siRNAs directed at other MBOAT members, inhibited ghrelin acylation in these cells. This study further supported the hypothesis that only GOAT contributes to the acylation of ghrelin (Gutierrez et al., 2008). To further exclude effects of endogenous factors, these investigators used HEK-293 cells that neither express ghrelin nor GOAT. HEK-293 cells cotransfected with preproghrelin and GOAT started secreting octanoylated ghrelin. Further, octanoylation of ghrelin was only achieved by GOAT, but not by other members of the MBOAT family, including MBOAT1, MBOAT2, MBOAT3, MBOAT5, human-BB1, porcupine, and FKSG89 (Gutierrez et al., 2008). Treatment of HEK-293 cell with a variety of substrate lipids including tetradecanoic acid caused acylation of ghrelin (Gutierrez et al., 2008). This result suggests that GOAT utilizes fatty acid substrates for acylation in addition to octanoic and decanoic acid. Considering the high degree of similarity in GOAT proteins across many vertebrates, HEK-293 cells were transfected with rat, mouse or zebrafish GOAT. All GOAT constructs resulted in successful octanoylation of human ghrelin, indicating that the function of GOAT is highly conserved across vertebrate species (Gutierrez et al., 2008).

\section{EXPRESSION AND DISTRIBUTION OF GOAT}

\section{Tissue distribution of GOAT}

In mice, the highest levels of GOAT mRNA are expressed in the stomach and intestine followed by testis (Yang et al., 2008a). In rats, GOAT mRNA is also expressed in hypothalamus, stomach, intestine, ovary, serum, placenta, muscle, heart, and adrenal glands (Gonzalez et al., 2008). Gutierrez et al. (Gutierrez et al., 2008) demonstrated that GOAT transcripts were most abundant in stomach and pancreas in humans. Studies indicate that stomach is the main source for production of acyl ghrelin. The number of GOAT-immunoreactive ghrelin cells in mouse stomach is much higher than rat stomach (Stengel et al., 2010). A study performed by An et al. (An et al., 2010) showed that GOAT mRNA and protein were present in the whole pancreas, isolated islets and INS-1 cells. GOAT immunoreactive cells were mainly localized in the periphery of rat islets. GOAT is also expressed in the hypothalamus and pituitary and its levels increase in response to fasting in mice (Gahete et al., 2010). Overall, GOAT appears to be predominantly expressed in stomach, brain and pancreas, all of which play important roles in the regulation of food intake and energy homeostasis.

\section{Regulation of GOAT expression}

A number of studies have reported that GOAT expression corresponds with organism energy levels (Gahete et al., 2010). Levels of GOAT increase during fasting in mice, while decreasing in states of positive energy balance status such as diet-induced obese (DIO) and db/db mice (Xu et al., 2009). Chronic malnutrition, achieved by $70 \%$ restriction in food intake for $21 \mathrm{~d}$, was reported to increase in GOAT ex- 
pression in the gastric mucosa, while a $48 \mathrm{~h}$ fast demonstrated no effect on GOAT mRNA transcription in rats (Gonzalez et al., 2008). In contrast, a 35\% dietary food restriction for 5 mo has been reported to significantly reduce levels of GOAT in the stomach (Reimer et al., 2010). Kirchner et al. (Kirchner et al., 2009) reported that expression of GOAT was decreased after $12,24,36$, and $48 \mathrm{~h}$ of fasting. Differences between studies may be attributed to species diversity and different energy restriction protocols.

GOAT is regulated by insulin. Studies by An et al. (An et al., 2010) showed that insulin inhibited the expression of GOAT mRNA and its promoter activity via a mammalian target of rapamycin (mTOR)-dependent mechanism. mTOR was activated by insulin. Blocking mTOR signaling by either rapamycin or overexpression of its negative regulators, tuberous sclerosis complex 1 (TSC1) or TSC2, increased the transcription and translation of GOAT. Pretreatment of INS-1 cells with rapamycin or overexpression of TSC1 or TSC2 attenuated the inhibitory effect of insulin on the transcription and translation of GOAT (An et al., 2010).

\section{CHARACTERISTICS OF GOAT}

GOAT is a member of the MBOAT superfamily (Hofmann, 2000), which is composed of many multi-spanning membrane proteins conserved from prokaryotes to eukaryotes. MBOAT members have been shown to be critical for lipid biosynthesis, sterol acylation, and acyl modification of secreted proteins (Chen et al., 2004; Petrova et al., 2013; Takada et al., 2006). MBOAT family contains a highly conserved asparagine and an invariant histidine, which are proposed to be catalytic. Two additional regions of conservation exist at the $\mathrm{N}$ - and $\mathrm{C}$-terminal boundaries of loop 5 on GOAT, where it adjoins surrounding hydrophobic regions (Taylor et al., 2013). Knowledge of GOAT architecture is important for a better understanding about how GOAT and other MBOATs function, and is a crucial precondition for the discovery of selective inhibitors for these enzymes.

\section{Structure and architectural organization}

In 2013, Taylor et al. (Taylor et al., 2013) studied the architectural organization of GOAT by predicting topology through bioinformatics modeling, then using selective permeabilization to verify its predicted localization to the endoplasmic reticulum. Using the V5Glyc tag and gel shift blotting to probe the architecture around His-338, they identified two predominant bands suggesting generation of two separate GOAT species (Taylor et al., 2013).

$\mathrm{N}$ and $\mathrm{C}$ termini were found to be on opposite sides of the membrane, requiring an odd number of transmembrane domains (TMs) (Taylor et al., 2013). Both positions 5 and 6 were found to be cytosolic, suggesting that the strongly predicted, hydrophobic C6 does not cross the membrane. Myc tag labeling of the conserved domain of MBOAT localized residue Asn-307 to the cytosol. To determine the topology around position 9 and the location of the conserved His-338, a novel dual topology reporter, V5Glyc tag, was developed. This technique allowed sensitive readout of topology by both glycosylation gel shift Western blotting and selective permeabilization immunofluorescence microscopy. Because $\mathrm{N}$-linked glycosylation only occurs in the endoplasmic reticulum lumen, the luminal N-terminus of GOAT is glycosylated completely, whereas the cytosolic C-terminus has no glycosylation. Position 9, immediately adjacent to the His-338 residue, was found to be luminal by both peptide- $N$-glycosidase sensitivity analysis and selective permeabilization. Subsequent analysis with chromatography, sedimentation velocity and MALDI (matrix-assisted laser desorption-ionization)-TOF (time-of-flight) mass spectrometry identified Met-56 as an alternate start codon. Because Met-56 is predicted to be the last (lumen) residue in TM-2, this finding suggests that GOAT lacking its first two TMs might be stable (Taylor et al., 2013). This may also be a physiologic product. Both M56A and M56I mutants eliminated the production of the lower band detected by gel shift blotting.

GOAT was verified to contain 11 transmembrane helices and one reentrant loop. Consistent with other member of the MBOAT family, the invariant residue His-338 and conserved Asn-307 are located in the endoplasmic reticulum (ER) lumen and cytosol respectively, making it unlikely that both are involved in catalysis. Photo cross-linking of synthetic ghrelin analogs and inhibitors demonstrates that the C-terminal region of GOAT is critical for binding reaction substrates, while lumenal His-338 mainly affects its activity (Taylor et al., 2013).

\section{Enzymatic characterization}

In 2012, Ohgusu et al. (Ohgusu et al., 2012) summarized a broad range of factors affecting the enzymatic activity of GOAT. Among these are detergents, acyl donors and substrate of GOAT as well as temperature, $\mathrm{pH}$ and cations.

Subcellular fractionation revealed that GOAT was a membrane-bound enzyme and its n-octanoyltransferase activity partitions with the cell membrane fraction (Gutierrez et al., 2008; Yang et al., 2008a). Treatment of the membrane fraction with CHAPS or Tween 80 retained GOAT activity. In contrast, treatment with six other detergents, including Triton X-100, Triton X-45, Lubrol, NP40, NP9, and Brij96v, attenuated or abolished GOAT activity. These findings indicate that CHAPS and Tween 80 stabilize the conformation of GOAT and are useful for solubilization of the enzyme (Ohgusu et al., 2012).

To determine if GOAT utilizes only n-octanoyl-CoA as an acyl donor, Ohgusu et al. (Ohgusu et al., 2009) incubated various n-acyl-CoAs, including n-hexanoyl-, n-decanoyl-, n-palmitoyl-, and n-myristoyl-CoA with recombinant GOAT and desacyl-ghrelin. The reaction products were subjected to high-performance liquid chromatography 
(HPLC) analysis to confirm the molecular structure by comparison with synthetic standard peptides. In addition to n-octanoyl CoA, GOAT modified the desacyl-ghrelin peptide with other medium-chain acyl acids, such as n-hexanoyl-CoA and n-decanoyl-CoA. Long-chain fatty acids were not used as acyl donors. Further, kinetic studies using desacyl-ghrelin and three medium-chain acyl-CoAs as donor substrates revealed substrate preference as nhexanoyl-CoA $>$ n-octanoyl-CoA $>$ n-decanoyl-CoA (Ohgusu et al., 2009).

These investigators examined the peptide substrate specificity of GOAT using different length (four to eight amino acids) of synthetic peptide substrates derived from the $\mathrm{N}$-terminal sequence of mammalian ghrelin (Ohgusu et al., 2009). These substrates were shorter than desacyl-ghrelin with an-amide structure at the C-terminal. Short synthetic ghrelin peptides ranging from four to eight amino acids and n-octanoyl-CoA were used as peptide and acyl donor substrates, respectively. HPLC analysis indicated that all five synthetic ghrelin-derived substrates delay the retention times for reaction products. The synthetic n-octanoylmodified peptide GSS(C8:0)FLSPK- $\mathrm{NH}_{2}$ had the same retention time as that of the GOAT-reacted GSSFLSPK-NH product. These findings indicate that these five peptides serve as GOAT substrates that are modified by n-octanoic acid. Peptides as short as four amino acids are sufficient to serve as GOAT substrates (Ohgusu et al., 2009).

The optimal temperature and $\mathrm{pH}$ for GOAT activity were also determined. The optimal reaction temperature was from 37 to $50^{\circ} \mathrm{C}$. GOAT activity was retained at $55^{\circ} \mathrm{C}$ but abolished over $60^{\circ} \mathrm{C}$ (Ohgusu et al., 2012). Optimal pH for maximal specific activity was $\mathrm{pH} 7.0-7.5$. The specific activity reduced rapidly below $\mathrm{pH} 6.5$ or over $\mathrm{pH} 8.5$. Some cations have effects on GOAT activity as well. Recombinant GOAT was activated by low concentrations but inhibited by high concentrations of $\mathrm{Mg}^{2+}$ and $\mathrm{Ca}^{2+}$, while $\mathrm{Fe}^{3+}$ and $\mathrm{Cu}^{2+}$ potently inhibited GOAT activity. Ethylenediaminetetraacetic acid (EDTA) and ethylene glycol tetraacetic acid (EGTA) did not affect GOAT activity, indicating GOAT has no absolute requirement for cations (Ohgusu et al., 2012).

\section{GOAT/ACYL-GHRELIN SYSTEM AND ENERGY METABOLISM}

Ghrelin is the only known peripherally produced and centrally acting peptide hormone stimulating food intake. Acyl-ghrelin promotes a positive energy balance by increasing food intake and reducing energy expenditure, therefore leading to an increase in body weight and adiposity (Tschop et al., 2000). As mentioned above, GOAT is responsible for ghrelin post-translational modification at its Ser3. The acylation is required for ghrelin to bind with and activate its receptor GHS-R1a. Thus, GOAT and acylghrelin are critical for the biological functions of ghrelin-

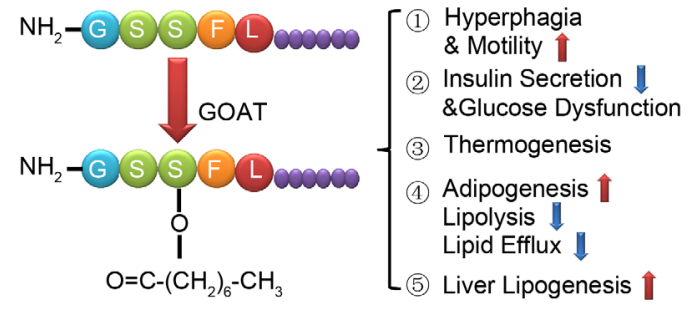

Figure 1 Roles of GOAT/acyl-ghrelin system in energy metabolism. Octanoylation of ghrelin (sequence as: GSSFLSPEHQKAQQRKESKKPPAKLQPR) by ghrelin O-acyltransferase (GOAT) on its third amino acid (serine-3) is necessary for the hormone's biological functions, Octanoylated ghrelin regulates food intake by inducing hyperphagia and increasing gastrointestinal motility, modulates glucose metabolism by altering insulin secretion and sensitivity, as well as stimulates adiposity by increasing lipid storage and/or decreasing lipid expenditure.

GHS-R1a signaling in hormonal secretions, memory and learning processes, food intake, body weight gain, insulin release, $\beta$-cell survival, adiposity, energy homeostasis, inflammatory processes, as well as in the development and progression of several types of cancers. Here, we focus on their relevance to energy metabolism (Figure 1).

\section{GOAT/acyl-ghrelin system on ingestive behavior}

Acyl-ghrelin earns its name as the "hunger hormone" because circulating acyl-ghrelin levels rise during fasting and between meals, while decreasing in the post-prandial state (Cummings et al., 2001). The hormone exerts its orexigenic effects by acting on hypothalamic neurons crucial for the regulation of feeding behavior and energy metabolism. Acyl-ghrelin activates neuropeptide Y (NPY)- and agouti-related peptide (AgRP)-producing neurons in the arcuate nucleus (Nakazato et al., 2001), probably through the mTORC1/S6K1 signaling dependent mechanism (Stevanovic et al., 2013) to increase the secretion of NPY, AgRP and gamma butyric acid (GABA). NPY subsequently modulates the activity of postsynaptic secondary order neurons in the paraventricular nucleus, dorsomedial nucleus and lateral hypothalamic area to stimulate food intake, while GABA inactivates proopiomelanocortin neurons and inhibits the anorectic melanocortin signaling pathway. Acylghrelin reaches the hypothalamus through three different pathways: via the systemic circulation by crossing the blood-brain barrier, through vagal afferent nerves, and by local synthesis in the hypothalamus where it may exert paracrine effects (Lim et al., 2011). The regulation of food intake by acyl-ghrelin is tightly dependent on metabolic status. Administration of exogenous acyl-ghrelin induces hyperphagia only in free-feeding rats but not in animals under negative metabolic conditions such as fasting or in chronic food-restriction (Alen et al., 2013). Acyl-ghrelin has also been shown to increase energy intake in situations of impaired appetite or cachexia, a common problem in cancer patients (Molfino et al., 2013).

Acyl-ghrelin is also a strong gastrokinetic agent, having 
the motilin-like ability to stimulate motility in the gastrointestinal tract (Trudel et al., 2002). Acyl-ghrelin triggers the migrating motor complex in the fasted state (De Winter et al., 2004; Fujino et al., 2003; Tack et al., 2006) and accelerates gastric emptying in the postprandial state in both rodents and humans (Asakawa et al., 2001; Levin et al., 2006). Acyl-ghrelin accelerates the transit of the small intestine but not the colon (Trudel et al., 2002). The prokinetic effect of acyl-ghrelin on gastrointestinal motility is mediated through activation of vagal afferents because atropine or vagotomy blocks the contractions elicited by ghrelin in urethane-anesthetized rats (Fujino et al., 2003; Fukuda et al., 2004).

\section{GOAT/acyl-ghrelin system, insulin release and glucose metabolism}

Pharmacological treatment or genetic manipulation of ghrelin in rodents indicates that GOAT/acyl-ghrelin system regulates glucose-stimulated secretion of insulin (GSIS). Despite the report by Lee et al. (Lee et al., 2002) showing that systemic administration of acyl-ghrelin enhances insulin secretion in rats, most rodent data support the concept that acute systemic administration of acyl-ghrelin inhibits insulin secretion. Pharmacological inhibition of the GOAT/acyl-ghrelin system with a GOAT inhibitor (Barnett et al., 2010) or GHS-R1a antagonist (Esler et al., 2007) significantly increases GSIS and improves glucose tolerance. These data indicate that antagonizing the GOAT/acylghrelin system improves glucose tolerance by enhancing GSIS in rodents. Consistent with pharmacological studies, genetic ablation of either ghrelin or GOAT leads to improved glucose tolerance and increased GSIS in mice fed a normal chow diet (Sun et al., 2006; Zhao et al., 2010). Further, improvement in hepatic and peripheral insulin sensitivities measured by hyperinsulinemic-euglycemic clamps has also been reported in ghrelin-deficient mice (Sun et al., 2006). Although GOAT-deficient mice subjected to insulin tolerance testing demonstrate similar insulin sensitivity relative to wildtype littermates (Kirchner et al., 2013), a more rigorous measure, such as hyperinsulinemic-euglycemic clamp, is needed to determine whether GOAT-null mice have altered insulin sensitivity.

Different from GOAT/acyl-ghrelin knockouts, mice lacking GHSR demonstrate similar glucose tolerance but decreased GSIS compared with wildtype littermates. This observation suggests that GHSR ablation improves insulin sensitivity (Lin et al., 2011; Longo et al., 2008). Data from hyperinsulinemic-euglycemic clamps showed a significant increase in glucose infusion rate, glucose disposal, and a decrease in endogenous glucose production in GHSR-null mice. These findings indicate that peripheral and hepatic insulin sensitivities are both enhanced in the absence of GHSR signaling (Lin et al., 2011; Qi et al., 2011).

Chronic application of rapamycin has been associated with new onset diabetes in patients with organ transplanta- tion. Studies by Xu et al. (Xu et al., 2012) have demonstrated that systematic injection of rapamycin significantly increased gastric ghrelin/GOAT expression, as well as circulating acyl-ghrelin. This effect is likely mediated by an increase in GOAT transcription induced by rapamycin. The derangement in glucose metabolism induced by systemic rapamycin was significantly attenuated by ghrelin receptor antagonism or genetic deletion (Xu et al., 2012). These findings suggest that GOAT/acyl-ghrelin contributes to rapamycin induced glucose dysfunction.

\section{GOAT/acyl-ghrelin system and thermogenesis and en- ergy expenditure}

Relative to the well-established role of ghrelin in the regulation of feeding behavior, its actions in thermogenesis and energy expenditure remains to be fully elucidated. Studies have revealed a biphasic action of acyl-ghrelin on thermogenesis, reducing body temperature at low doses (Lawrence et al., 2002), while increasing it at high doses (Jaszberenyi et al., 2006). Consistent with this observation, ghrelin gene knockout mice showed an impairment in the control of body temperature under extreme thermic conditions (Szentirmai et al., 2009). Ghrelin may contribute to the regulation of thermogenesis via a central mechanism because areas of the hypothalamus located in the vicinity of cold-sensitive neurons exhibit ghrelin-binding sites (Wiedmer et al., 2011). Contradicting this study, both GHSR-KO (Szentirmai et al., 2009) and GOAT-KO mice (Heppner et al., 2013) maintained a similar body core temperature relative to wild type counterparts under thermic stress. Further, administration of acyl-ghrelin did not alter body temperature in mice, rats, and humans (Wiedmer et al., 2011). In this context, the actions of alternative ghrelin gene-derived peptides such as obestatin could be important. Obestatin has been shown to attenuate the hypothermic response of ghrelin gene $\mathrm{KO}$ mice (Szentirmai et al., 2009). These sometimes conflicting observations suggest a complex regulation of body temperature by the GOAT/acyl-ghrelin system.

\section{GOAT/acyl-ghrelin system and lipid metabolism}

Chronic central administration of acyl-ghrelin increases adipose deposition independent of food intake in pair-fed animals. Although total energy expenditure and spontaneous physical activity remained unchanged, respiratory quotient was significantly increased, indicating greater carbohydrate metabolism instead of lipid substrate consumption. Further studies demonstrated that central ghrelin stimulated triglyceride (TG) uptake and lipogenesis, while inhibited lipid oxidation in white adipocytes. The mRNA expression of various fat storage-promoting enzymes such as lipoprotein lipase, acetyl-CoA carboxylase, fatty acid synthase, and stearoyl-CoA desaturase-1 were markedly increased (Theander-Carrillo et al., 2006), while levels of the ratelimiting enzymes in fat oxidation such as carnitinepalmitoyltransferase- $1 \alpha$ were significantly decreased. In brown 
adipocytes, intracerebroventricular injection of ghrelin decreased the expression of uncoupling proteins (UCPs) in a dose-dependent manner. This effect was independent of acyl-ghrelin-induced hyperphagia, and was mediated by the sympathetic nervous system (Theander-Carrillo et al., 2006). Intact $\beta$-adrenergic signaling is required for acylghrelin induced increases in adipose tissue deposits.

Peripheral daily administration of acyl-ghrelin for two weeks caused a significant increase in fat mass as measured by dual energy X-ray absorptiometry (Tschop et al., 2000). As ghrelin receptor null mice were unresponsive to acyl-ghrelin, it is proposed that this effect is mediated by the ghrelin receptor GHS-R1a. This concept was further supported by the observation that blockade of the ghrelin receptor abolished the effect of acyl-ghrelin on adiposity (Davies et al., 2009). In vitro experiments demonstrated that ghrelin increases white adipose tissue volume by either stimulating adipogenesis or inhibiting lipolysis and lipid efflux from adipocytes. In cultured epididymal adipocytes, application of acyl-ghrelin decreased the expression of ABCG1, the primary mediator of cholesterol efflux (Vaughan and Oram, 2005), and inhibited glycerol release (Tsubone et al., 2005), leading to the increase lipid accumulation in adipocytes.

Acyl-ghrelin-induced lipid accumulation is not limited to white adipose tissues. In mouse liver, acyl-ghrelin significantly elevated the number of lipid droplets, total lipid area and triacylglycerol content ( $\mathrm{Li}$ et al., 2014) as well as lipogenesis related genes. In contrast, ghrelin demonstrated no effect on hepatic lipogenesis in GHSR1a null mice (Li et al., 2014). The effects of acyl-ghrelin on lipogenesis were mediated by the mTOR/PPAR $\gamma$ signaling pathway.

\section{RELATION BETWEEN GOAT/ACYL-GHRELIN SYSTEM AND OBESITY}

It has been well described that plasma acyl-ghrelin levels are negatively correlated to body mass index (BMI) (Shiiya et al., 2002), which means that lean phenotype is associated with high levels of acyl-ghrelin and obesity with low levels of ghrelin. The reasons for this negative relation are unknown, but might be explained by the adaptive response of organism. Systemic or intracerebroventricular administration of ghrelin induces hyperphagia, weight gain, and increased adiposity (Nakazato et al., 2001; Tschop et al., 2000). Chronic central administration of ghrelin increases adipose deposition independent of food intake in pair-fed animals (Nakazato et al., 2001; Theander-Carrillo et al., 2006). Consistent with these observations, ghrelin receptor null mice are protected against the full development of diet-induced obesity (Zigman et al., 2005).

In addition to its expression in gastric mucosa, GOAT is present in the circulation with levels dependent on metabolic status. In the clinical study performed by Goebel-Stengel et al. (Goebel-Stengel et al., 2013), subjects with normal weight, anorexic subjects, and obese subjects with BMI 30-40, 40-50 and >50 were recruited. After overnight fasting, anorexic patients showed reduced circulating GOAT protein levels whereas obese patients with BMI $>50$ had increased concentrations compared to normal weight controls. In contrast to circulating GOAT, ghrelin levels were higher in anorexic patients. Plasma GOAT protein levels correlated positively with BMI, and negatively with ghrelin (Goebel-Stengel et al., 2013). These observations indicate that GOAT may counteract the adaptive changes of ghrelin observed under these conditions and potentially contribute to the development or maintenance of anorexia and obesity.

\section{PHYSIOLOGICAL ALTERATIONS OF GOAT KNOCKOUT MICE}

Generation of GOAT null mice has provided an indispensible tool to explore the physiological functions of acylghrelin. Two GOAT knockout mouse lines have been reported (Gutierrez et al., 2008; Zhao et al., 2010). Both demonstrated the absence of acyl-ghrelin in blood and significantly higher levels of desacyl-ghrelin relative to wild-type littermates. With normal chow diet feeding, they had normal body weight and fat mass (Kirchner et al., 2009). When fed a high fat diet (HFD), these GOAT knockout mice displayed significantly lower body weights compared to wild-type animals, without significant change in body composition. Challenging GOAT knockout mice with HFD rich in medium chain triglycerides significantly reduced body weight and fat mass compared to wild-type littermates (Kirchner et al., 2009). This effect is likely due to increased energy expenditure, since food intake was higher in the GOAT knockout mice (Kirchner et al., 2009). The other GOAT knockout mouse line generated by Zhao et al. (Zhao et al., 2010) showed identical body weight, body composition and food intake as wild-type littermates, whether fed normal chow diet or HFD. Further, weight loss curves remained the same when subjected to a severe (60\%) caloric restriction protocol (Zhao et al., 2010). Although fasting blood glucose initially declined equally in wild-type and $\mathrm{GOAT}^{--}$mice under $60 \%$ caloric restriction, glucose levels stabilized in wildtype mice while continuing to decline in $\mathrm{GOAT}^{-/-}$mice after day 4. On day $7, \mathrm{GOAT}^{-/-}$mice were moribund, while wildtype mice showed normal physical activity. Infusion of either ghrelin or growth hormone normalized blood glucose in $\mathrm{GOAT}^{-/-}$mice and prevented death (Zhao et al., 2010), suggesting that acyl-ghrelin is required to maintain blood glucose levels through growth hormone secretion during periods of caloric restriction.

GOAT-mediated acylation of ghrelin is a critical modulator of food reward. Following 24-hour food deprivation, GOAT-deficient mice displayed an attenuated motivation for food in an operant responding model (Davis et al., 
2012). Regarding hedonic feeding, ghrelin administration increased operant lever pressing for sucrose, peanut butter-flavored sucrose or HFD pellets in rodents. On the other hand, GHSR antagonist reduced operant responding for sucrose solution (Finger et al., 2012; Landgren et al., 2012; Perello et al., 2010; Skibicka et al., 2012). GOAT knockout mice showed a decreased hedonic feeding response as examined in a "dessert effect" protocol, in which the intake of a palatable HFD "dessert" was evaluated in calorically-sated mice (Davis et al., 2012).

Not only can ghrelin control food intake, it also affects macronutrient selection (Shimbara et al., 2004). Studies by Shin et al. (Shin et al., 2010) demonstrated that ghrelin, GOAT, GHS-R1a and prohormone convertase 1/3 (PC 1/3) were expressed in Type I, II, III and IV taste cells of mouse taste buds, indicating that they could play local modulatory roles in taste perception. In 2013, Cai et al. (Cai et al., 2013) revealed that both ghrelin ${ }^{-/-}$and $\mathrm{GOAT}^{-/-}$mice exhibited reduced lipid taste sensitivity, while $\mathrm{GOAT}^{-1-}$ mice demonstrated increased salty taste sensitivity compared to wildtype control littermates. Given the evidence of a positive correlation between overall fat preference and percentage of body fat in human studies (Mela and Sacchetti, 1991), the ghrelin/GOAT system may play a local modulatory role in determining taste cell function and signaling. Taken together, these results suggest that the motivation to obtain food and macronutrient selection is regulated by endogenous GOAT activity.

In 2012, a metabolomics analysis of plasma samples and gene expression analysis of tissues taken from $\mathrm{GOAT}^{-/-}$ mice highlighted significant changes in bile acid metabolites and relevant transporters (Kang et al., 2012). Serum metabolite profile analysis revealed secondary bile acids are increased by more than 2.5 -fold in $\mathrm{GOAT}^{-/-}$mice. This effect was attributed to increased expression of the ileal sodium-dependent bile acid transporter in the intestinal and biliary tract. Further, a number of up-regulated solute carrier family genes were identified by microarray analysis of the intestinal tract of $\mathrm{GOAT}^{-/-}$mice (Kang et al., 2012). Among these was Slc5a12. Slc5a12 is highly expressed in the proximal regions of the small intestine and serves as a low affinity transporter for short-chain monocarboxylate, such as lactate, short-chain fatty acids, and $\beta$-hydroxy-butyrate from dietary sources (Srinivas et al., 2005; Teramae et al., 2010). These findings suggest an additional role of the ghrelin/GOAT system in the regulation of bile acid metabolism.

\section{THERAPEUTIC STRATEGIES TARGETING GOAT/ACYL-GHRELIN SYSTEM}

Discovery of the importance of ghrelin acylation for its activity has enriched the known repertoire of posttranslational-modification processes and opened the possibility of as- sessing the physiological role of ghrelin and desacyl ghrelin by targeting GOAT. Inhibition of GOAT is a novel strategy distinct from previous strategies such as inhibition of the synthesis and/or secretion of ghrelin. Inhibition of GOAT would impede the production of acyl-ghrelin and simultaneously increase the level of desacyl-ghrelin, which could also be beneficial for glucose homeostasis.

\section{GOAT inhibitor: GO-CoA-Tat}

Since GOAT is essential for the production of acyl-ghrelin, inhibition of the GOAT represents a novel approach to suppress the ghrelin system. A peptide based bisubstrate analog with potent inhibition of GOAT activity has been developed by Barnett and colleagues and named GO-CoA-Tat (Barnett et al., 2010).

\section{Discovery of GO-CoA-Tat}

Previous investigations on serotonin $\mathrm{N}$-acetyltransferase, using bisubstrate analogs, showed that installing an acetyl bridge between the amine substrate and CoA potently inhibited this enzyme (Khalil et al., 1999). This strategy has been also used for histone acetyltransferases (Lau et al., 2000). The bisubstrate analog GO-CoA-Tat has been designed based on the theory that if GOAT uses a ternary complex mechanism which templates octanoyl-CoA and ghrelin peptide, then linking the two substrates with a non-cleavable bridge could combine the binding energies of the individual ligands without the entropic loss associated with forming the ternary complex (Barnett et al., 2010). To assure that the synthesis peptide would be recognized by GOAT, amino acids 1-10, which are highly conserved, were selected for coupling to octanoyl-CoA. An 11-mer HIV Tat-derived peptide sequence was attached to the $\mathrm{C}$ terminus via an amino-hexanoyl linker to enhance cell penetration (Barnett et al., 2010). In vitro studies on two cell lines stably expressing GOAT and preproghrelin showed that GO-CoATat inhibited the production of acyl-ghrelin but not desacyl ghrelin. Administration of GO-CoA-Tat to wild type C57BL6 animals fed with a medium chain trigylceride (MCT) diet decreased serum levels of acyl-ghrelin with maximum inhibition $6 \mathrm{~h}$ after administration. Consistent with in vitro studies, there was no significant effect on serum levels of desacyl ghrelin (Barnett et al., 2010).

\section{Effects of GO-CoA-Tat on energy metabolism}

Chronic GO-CoA-Tat treatment prevented the significant weight gain observed in vehicle-treated mice fed MCT-rich HFD (Barnett et al., 2010). Quantitative magnetic resonance measurements showed that mice treated with GO-CoA-Tat displayed significantly lower fat mass, but not lean mass (Barnett et al., 2010). Another study performed on Siberian hamsters also demonstrated significant effects of GO-CoATat on food deprivation-induced increases in ingestive behavior (Teubner et al., 2013). After $48 \mathrm{~h}$ food deprivation, GO-CoA-Tat attenuated food foraging, food intake, and 
food hoarding post-refeeding relative to animals treated with saline. In addition, GO-CoA-Tat treated mice showed lower blood glucose.

Pre-treatment of human islet cells with GO-CoA-Tat significantly increased insulin release in response to a glucose challenge, suggesting that acyl-ghrelin plays a direct role in blunting insulin response (Barnett et al., 2010). Similar results have been detected in mice treated with GO-CoA-Tat. These mice showed a significant increase in insulin release induced by glucose, which was accompanied by a reduction in blood glucose. The effects of GO-CoA-Tat on insulin release and glucose metabolism were significantly attenuated in ghrelin knockout animals relative to wild-type mice (Barnett et al., 2010). These observations support the hypothesis that GO-CoA-Tat effects on glucose homeostasis are mediated by inhibition of acyl-ghrelin.

\section{Peptide or nonpeptide small molecule inhibitors}

As a peptide-based inhibitor, GO-CoA-Tat has limitations. Synthetic derivatives are anticipated in order to further maximize pharmacodynamic and/or pharmacokinetic properties. This is crucial when used to treat obesity and type 2 diabetes. Although early results are promising, the efficacy for obesity treatment by GO-CoA-Tat remains to be proven. It is important to note that although mice used in these studies were maintained on a high fat diet, they did not have pre-existing obesity at the beginning of the treatment. Obese humans or rodents may respond less well to GOAT inhibition as the ghrelin system is already suppressed (Patterson et al., 2011)

In 2008, an acyl-ghrelin product analog Dap ${ }^{3}$-ghrelin was designed to block GOAT activity in an in vitro biochemical study (Yang et al., 2008b). GOAT recognizes several amino acids in proghrelin that surround the site of octanoylation at serine-3. A pentapeptide containing only the $\mathrm{N}$-terminal five amino acids of proghrelin (GSSFL) inhibits the octanoylation of proghrelin only when its $\mathrm{C}$ terminus is amidated. The mutant GSAFL- $\mathrm{NH}_{2}$ pentapeptide also inhibits GOAT. Thus, the unacylated pentapeptide appears to inhibit GOAT by competing for the peptide binding site and not necessarily by serving as substrate for octanoylation. Octanoylation of proghrelin is inhibited more efficiently when the amidated pentapeptide contains an octanoyl in ester linkage to serine-3, thereby mimicking the product of the reaction. Inhibitory activity is significantly increased when full-length ghrelin (1-28) or the amidated ghrelin pentapeptide contains an octanoylated diaminopropionic acid (Dap) in place of the octanoylated serine at residue 3 (Yang et al., 2008 b). The increased inhibitory potency of the octanoylated ghrelin peptides with an amide linkage at residue 3 , instead of an ester linkage, may help guide the design of potent small molecule inhibitors of GOAT.

In 2011, Garner's group (Garner and Janda, 2011) identified two potential non-peptide small molecule antagonists of GOAT by using an enzyme assay based on cat-ELCCA. Two compounds were discovered and named as compounds $3 \mathrm{a}$ and $3 \mathrm{~b}$; both were found to exhibit dose-dependent antagonism of GOAT. Based on the structures of compounds $3 \mathrm{a}$ and $3 \mathrm{~b}$, these compounds may block octanoyl-CoA from binding to GOAT since each contains a long alkyl chain similar to that found in octanoyl-CoA. It remains to be determined whether these non-peptide antagonists of GOAT are more potent than their peptide counterparts.

\section{Targeting GOAT versus GHS-R1a}

Two different strategies have been developed to block ghrelin receptor (GHS-R1a) signaling: antagonizing ghrelininduced signaling or blocking the high constitutive activity by an inverse agonist. These strategies have led to the evaluation of a group of GHS-R1a neutral competitive antagonists and inverse agonists. Unfortunately, no ghrelin receptor antagonist is currently available in the market, mainly due to deficient efficacy, selectivity, low potency, poor bioavailability or side effects.

Directly targeting the biosynthesis of the active acylghrelin by inhibiting GOAT, offers several potential advantages over receptor antagonism. First, enzyme inhibitors are not required to cross the blood-brain barrier, because the main source of ghrelin/GOAT is from stomach, while many of the key action sites for ghrelin receptor antagonist are located in the brain. Second, receptor antagonists may drive higher acyl-ghrelin production and increase acyl/desacyl ghrelin ratios, which will blunt their long-term efficacy. A similar strategy has been demonstrated to be efficient for treatment of lipid dysfunction and some types of cancer by targeting other GOAT-related MBOAT family members. Finally, it is easier to develop small-molecule inhibitors of GOAT than receptor antagonists or inverse agonists.

\section{Tissue specific interference of GOAT}

At present, data assessing tissue specific regulation of GOAT expression are lacking. Tissue-specific genetic ablation of GOAT will enable clarification of the paracrine role of ghrelin in different tissues. Considering levels of expression and functional relevance, particular emphasis should be given to the stomach, pancreas and hypothalamus. Another question is whether GOAT is regulated in response to the physiological environment. This seems likely to be the case because acyl-ghrelin levels fall significantly as the result of long-term fasting despite an increase in total ghrelin concentration.

Compliance and ethics The author(s) declare that they have no conflict of interest.

Acknowledgements This work was supported by the National Natural Science Foundation of China (81330010, 81390354) and American Diabetes Association grant (1-13-BS-225). 
Alen, F., Crespo, I., Ramirez-Lopez, M.T., Jagerovic, N., Goya, P., de Fonseca, F.R., de Heras, R.G., and Orio, L. (2013). Ghrelin-induced orexigenic effect in rats depends on the metabolic status and is counteracted by peripheral CB1 receptor antagonism. PLoS One 8, e60918.

An, W., Li, Y., Xu, G., Zhao, J., Xiang, X., Ding, L., Li, J., Guan, Y., Wang, X., Tang, C., Li, X., Mulholland, M., and Zhang, W. (2010). Modulation of ghrelin O-acyltransferase expression in pancreatic islets. Cell Physiol. Biochem 26, 707-716.

Asakawa, A., Inui, A., Kaga, T., Yuzuriha, H., Nagata, T., Ueno, N., Makino, S., Fujimiya, M., Niijima, A., Fujino, M.A., and Kasuga, M. (2001). Ghrelin is an appetite-stimulatory signal from stomach with structural resemblance to motilin. Gastroenterology 120, 337-345.

Barnett, B.P., Hwang, Y., Taylor, M.S., Kirchner, H., Pfluger, P.T., Bernard, V., Lin, Y.Y., Bowers, E.M., Mukherjee, C., Song, W.J., Longo, P.A., Leahy, D.J., Hussain, M.A., Tschop, M.H., Boeke, J.D., and Cole, P.A. (2010). Glucose and weight control in mice with a designed ghrelin O-acyltransferase inhibitor. Science 330, 1689-1692.

Bowers, C.Y., Reynolds, G.A., and Momany, F.A. (1984). New advances on the regulation of growth hormone $(\mathrm{GH})$ secretion. Internat. J. Neurol $18,188-205$.

Cai, H., Cong, W.N., Daimon, C.M., Wang, R., Tschop, M.H., Sevigny, J., Martin, B., and Maudsley, S. (2013). Altered lipid and salt taste responsivity in ghrelin and GOAT null mice. PLoS One 8, e76553.

Chen, M.H., Li, Y.J., Kawakami, T., Xu, S.M., and Chuang, P.T. (2004). Palmitoylation is required for the production of a soluble multimeric Hedgehog protein complex and long-range signaling in vertebrates. Genes Dev 18, 641-659.

Cummings, D.E., Purnell, J.Q., Frayo, R.S., Schmidova, K., Wisse, B.E., and Weigle, D.S. (2001). A preprandial rise in plasma ghrelin levels suggests a role in meal initiation in humans. Diabetes 50, 1714-1719.

Davies, J.S., Kotokorpi, P., Eccles, S.R., Barnes, S.K., Tokarczuk, P.F., Allen, S.K., Whitworth, H.S., Guschina, I.A., Evans, B.A., Mode, A., Zigman, J.M., and Wells, T. (2009). Ghrelin induces abdominal obesity via GHS-R-dependent lipid retention. Mol Endocrinol 23, 914-924.

Davis, J.F., Perello, M., Choi, D.L., Magrisso, I.J., Kirchner, H., Pfluger, P.T., Tschoep, M., Zigman, J.M., and Benoit, S.C. (2012). GOAT induced ghrelin acylation regulates hedonic feeding. Hormones Behav 62, 598-604

De Winter, B.Y., De Man, J.G., Seerden, T.C., Depoortere, I., Herman, A.G., Peeters, T.L., and Pelckmans, P.A. (2004). Effect of ghrelin and growth hormone-releasing peptide 6 on septic ileus in mice. Neurogastroenterol Motil 16, 439-446.

Esler, W.P., Rudolph, J., Claus, T.H., Tang, W., Barucci, N., Brown, S.E., Bullock, W., Daly, M., Decarr, L., Li, Y., Milardo, L., Molstad, D., Zhu, J., Gardell, S.J., Livingston, J.N., and Sweet, L.J. (2007). Small-molecule ghrelin receptor antagonists improve glucose tolerance, suppress appetite, and promote weight loss. Endocrinology 148, 5175-5185.

Finger, B.C., Dinan, T.G., and Cryan, J.F. (2012). Diet-induced obesity blunts the behavioural effects of ghrelin: studies in a mouse-progressive ratio task. Psychopharmacology 220, 173-181.

Fujino, K., Inui, A., Asakawa, A., Kihara, N., Fujimura, M., and Fujimiya, M. (2003). Ghrelin induces fasted motor activity of the gastrointestinal tract in conscious fed rats. J Physiol 550, 227-240.

Fukuda, H., Mizuta, Y., Isomoto, H., Takeshima, F., Ohnita, K., Ohba, K., Omagari, K., Taniyama, K., and Kohno, S. (2004). Ghrelin enhances gastric motility through direct stimulation of intrinsic neural pathways and capsaicin-sensitive afferent neurones in rats. Scandinavian J Gastroenterol 39, 1209-1214.

Gahete, M.D., Cordoba-Chacon, J., Salvatori, R., Castano, J.P., Kineman, R.D., and Luque, R.M. (2010). Metabolic regulation of ghrelin O-acyl transferase (GOAT) expression in the mouse hypothalamus, pituitary, and stomach. Mol. Cell Endocrinol 317, 154-160.

Garner, A.L., and Janda, K.D. (2011). A small molecule antagonist of ghrelin O-acyltransferase (GOAT). Chem Commun 47, 7512-7514.
Goebel-Stengel, M., Hofmann, T., Elbelt, U., Teuffel, P., Ahnis, A., Kobelt, P., Lambrecht, N.W., Klapp, B.F., and Stengel, A. (2013). The ghrelin activating enzyme ghrelin-O-acyltransferase (GOAT) is present in human plasma and expressed dependent on body mass index. Peptides 43, 13-19.

Gonzalez, C.R., Vazquez, M.J., Lopez, M., and Dieguez, C. (2008). Influence of chronic undernutrition and leptin on GOAT mRNA levels in rat stomach mucosa. J Mol Endocrinol 41, 415-421.

Gutierrez, J.A., Solenberg, P.J., Perkins, D.R., Willency, J.A., Knierman, M.D., Jin, Z., Witcher, D.R., Luo, S., Onyia, J.E., and Hale, J.E. (2008). Ghrelin octanoylation mediated by an orphan lipid transferase. Proc Natl Acad Sci USA 105, 6320-6325.

Heppner, K.M., Muller, T.D., Kirchner, H., Perez-Tilve, D., Pfluger, P.T., Tschop, M.H., and Hofmann, S.M. (2013). The role of ghrelinoctanoyl-acyl-transferase in thermoregulation. J Endocrinol Invest 36, $180-184$.

Hofmann, K. (2000). A superfamily of membrane-bound O-acyltransferases with implications for wnt signaling. Trends Biochem Sci 25, 111-112.

Howard, A.D., Feighner, S.D., Cully, D.F., Arena, J.P., Liberator, P.A., Rosenblum, C.I., Hamelin, M., Hreniuk, D.L., Palyha, O.C., Anderson, J., Paress, P.S., Diaz, C., Chou, M., Liu, K.K., McKee, K.K., Pong, S.S., Chaung, L.Y., Elbrecht, A., Dashkevicz, M., Heavens, R., Rigby, M., Sirinathsinghji, D.J., Dean, D.C., Melillo, D.G., Patchett, A.A., Nargund, R., Griffin, P.R., DeMartino, J.A., Gupta, S.K., Schaeffer, J.M., Smith, R.G., and Van der Ploeg, L.H. (1996). A receptor in pituitary and hypothalamus that functions in growth hormone release. Science 273, 974-977.

Jaszberenyi, M., Bujdoso, E., Bagosi, Z., and Telegdy, G. (2006). Mediation of the behavioral, endocrine and thermoregulatory actions of ghrelin. Horm Behav 50, 266-273.

Kang, K., Schmahl, J., Lee, J.M., Garcia, K., Patil, K., Chen, A., Keene, M., Murphy, A., and Sleeman, M.W. (2012). Mouse ghrelin-Oacyltransferase (GOAT) plays a critical role in bile acid reabsorption. FASEB J 26, 259-271.

Khalil, E.M., De Angelis, J., Ishii, M., and Cole, P.A. (1999). Mechanism-based inhibition of the melatonin rhythm enzyme: pharmacologic exploitation of active site functional plasticity. Proc Natl Acad Sci USA 96, 12418-12423.

Kirchner, H., Gutierrez, J.A., Solenberg, P.J., Pfluger, P.T., Czyzyk, T.A., Willency, J.A., Schurmann, A., Joost, H.G., Jandacek, R.J., Hale, J.E., Heiman, M.L., and Tschop, M.H. (2009). GOAT links dietary lipids with the endocrine control of energy balance. Nat Med 15, 741-745.

Kirchner, H., Heppner, K.M., Holland, J., Kabra, D., Tschop, M.H., and Pfluger, P.T. (2013). Ablation of ghrelin O-acyltransferase does not improve glucose intolerance or body adiposity in mice on a leptin-deficient ob/ob background. PLoS One 8, e61822.

Kojima, M., Hosoda, H., Date, Y., Nakazato, M., Matsuo, H., and Kangawa, K. (1999). Ghrelin is a growth-hormone-releasing acylated peptide from stomach. Nature 402, 656-660.

Landgren, S., Simms, J.A., Hyytia, P., Engel, J.A., Bartlett, S.E., and Jerlhag, E. (2012). Ghrelin receptor (GHS-R1A) antagonism suppresses both operant alcohol self-administration and high alcohol consumption in rats. Addict Biol 17, 86-94.

Lau, O.D., Kundu, T.K., Soccio, R.E., Ait-Si-Ali, S., Khalil, E.M., Vassilev, A., Wolffe, A.P., Nakatani, Y., Roeder, R.G., and Cole, P.A. (2000). HATs off: selective synthetic inhibitors of the histone acetyltransferases p300 and PCAF. Mol Cell 5, 589-595.

Lawrence, C.B., Snape, A.C., Baudoin, F.M., and Luckman, S.M. (2002). Acute central ghrelin and GH secretagogues induce feeding and activate brain appetite centers. Endocrinology 143, 155-162.

Lee, H.M., Wang, G., Englander, E.W., Kojima, M., and Greeley, G.H., Jr. (2002). Ghrelin, a new gastrointestinal endocrine peptide that stimulates insulin secretion: enteric distribution, ontogeny, influence of endocrine, and dietary manipulations. Endocrinology 143, 185-190.

Levin, F., Edholm, T., Schmidt, P.T., Gryback, P., Jacobsson, H., 
Degerblad, M., Hoybye, C., Holst, J.J., Rehfeld, J.F., Hellstrom, P.M., and Naslund, E. (2006). Ghrelin stimulates gastric emptying and hunger in normal-weight humans. J Clin Endocrinol Metab 91, 3296-3302.

Li, Z., Xu, G., Qin, Y., Zhang, C., Tang, H., Yin, Y., Xiang, X., Li, Y., Zhao, J., Mulholland, M., and Zhang, W. (2014). Ghrelin promotes hepatic lipogenesis by activation of mTOR-PPARgamma signaling pathway. Proc Natl Acad Sci USA 111, 13163-13168.

Lim, C.T., Kola, B., and Korbonits, M. (2011). The ghrelin/GOAT/GHS-R system and energy metabolism. Rev Endocr Metab Disord 12, 173-186.

Lin, L., Saha, P.K., Ma, X., Henshaw, I.O., Shao, L., Chang, B.H., Buras, E.D., Tong, Q., Chan, L., McGuinness, O.P., and Sun, Y. (2011). Ablation of ghrelin receptor reduces adiposity and improves insulin sensitivity during aging by regulating fat metabolism in white and brown adipose tissues. Aging Cell 10, 996-1010.

Longo, K.A., Charoenthongtrakul, S., Giuliana, D.J., Govek, E.K., McDonagh, T., Qi, Y., DiStefano, P.S., and Geddes, B.J. (2008). Improved insulin sensitivity and metabolic flexibility in ghrelin receptor knockout mice. Regul Pept 150, 55-61.

Mela, D.J., and Sacchetti, D.A. (1991). Sensory preferences for fats: relationships with diet and body composition. Am J Clin Nutr 53, 908-915

Molfino, A., Gioia, G., and Muscaritoli, M. (2013). The hunger hormone ghrelin in cachexia. Exp Opin Biol Ther 13, 465-468.

Nakazato, M., Murakami, N., Date, Y., Kojima, M., Matsuo, H., Kangawa, K., and Matsukura, S. (2001). A role for ghrelin in the central regulation of feeding. Nature 409, 194-198.

Ohgusu, H., Shirouzu, K., Nakamura, Y., Nakashima, Y., Ida, T., Sato, T., and Kojima, M. (2009). Ghrelin O-acyltransferase (GOAT) has a preference for n-hexanoyl-CoA over n-octanoyl-CoA as an acyl donor. Biochem. Biophys Res Commun 386, 153-158.

Ohgusu, H., Takahashi, T., and Kojima, M. (2012). Enzymatic characterization of GOAT, ghrelin O-acyltransferase. Methods Enzymol 514, 147-163.

Patterson, M., Bloom, S.R., and Gardiner, J.V. (2011). Ghrelin and appetite control in humans-potential application in the treatment of obesity. Peptides 32, 2290-2294.

Perello, M., Sakata, I., Birnbaum, S., Chuang, J.C., Osborne-Lawrence, S., Rovinsky, S.A., Woloszyn, J., Yanagisawa, M., Lutter, M., and Zigman, J.M. (2010). Ghrelin increases the rewarding value of high-fat diet in an orexin-dependent manner. Biol Psychiatry 67, 880-886.

Petrova, E., Rios-Esteves, J., Ouerfelli, O., Glickman, J.F., and Resh, M.D. (2013). Inhibitors of Hedgehog acyltransferase block Sonic Hedgehog signaling. Nat Chem Biol 9, 247-249.

Qi, Y., Longo, K.A., Giuliana, D.J., Gagne, S., McDonagh, T., Govek, E., Nolan, A., Zou, C., Morgan, K., Hixon, J., Saunders, J.O., Distefano, P.S., and Geddes, B.J. (2011). Characterization of the insulin sensitivity of ghrelin receptor KO mice using glycemic clamps. BMC Physiol 11, 1.

Reimer, R.A., Maurer, A.D., Lau, D.C., and Auer, R.N. (2010). Long-term dietary restriction influences plasma ghrelin and GOAT mRNA level in rats. Physiol Behav 99, 605-610.

Shiiya, T., Nakazato, M., Mizuta, M., Date, Y., Mondal, M.S., Tanaka, M., Nozoe, S., Hosoda, H., Kangawa, K., and Matsukura, S. (2002). Plasma ghrelin levels in lean and obese humans and the effect of glucose on ghrelin secretion. J Clin Endocrinol Metab 87, 240-244.

Shimbara, T., Mondal, M.S., Kawagoe, T., Toshinai, K., Koda, S., Yamaguchi, H., Date, Y., and Nakazato, M. (2004). Central administration of ghrelin preferentially enhances fat ingestion. Neurosci Lett 369, 75-79.

Shin, Y.K., Martin, B., Kim, W., White, C.M., Ji, S., Sun, Y., Smith, R.G., Sevigny, J., Tschop, M.H., Maudsley, S., and Egan, J.M. (2010). Ghrelin is produced in taste cells and ghrelin receptor null mice show reduced taste responsivity to salty $(\mathrm{NaCl})$ and sour (citric acid) tastants. PLoS One 5, e12729.

Skibicka, K.P., Hansson, C., Egecioglu, E., and Dickson, S.L. (2012). Role of ghrelin in food reward: impact of ghrelin on sucrose self-administration and mesolimbic dopamine and acetylcholine receptor gene expression. Addict Biol 17, 95-107.

Smith, R.G., Sun, Y., Betancourt, L., and Asnicar, M. (2004). Growth hormone secretagogues: prospects and potential pitfalls. Best Pract. Res Clin Endocrinol Metab 18, 333-347.

Srinivas, S.R., Gopal, E., Zhuang, L., Itagaki, S., Martin, P.M., Fei, Y.J., Ganapathy, V., and Prasad, P.D. (2005). Cloning and functional identification of slc5a12 as a sodium-coupled low-affinity transporter for monocarboxylates (SMCT2). Biochem J 392, 655-664.

Stengel, A., Goebel, M., Wang, L., Tache, Y., Sachs, G., and Lambrecht, N.W. (2010). Differential distribution of ghrelin-O-acyltransferase (GOAT) immunoreactive cells in the mouse and rat gastric oxyntic mucosa. Biochem Biophys Res Commun 392, 67-71.

Stevanovic, D., Trajkovic, V., Muller-Luhlhoff, S., Brandt, E., Abplanalp, W., Bumke-Vogt, C., Liehl, B., Wiedmer, P., Janjetovic, K., Starcevic, V., Pfeiffer, A.F., Al-Hasani, H., Tschop, M.H., and Castaneda, T.R. (2013). Ghrelin-induced food intake and adiposity depend on central mTORC1/S6K1 signaling. Mol Cell Endocrinol 381, 280-290.

Sun, Y., Asnicar, M., Saha, P.K., Chan, L., and Smith, R.G. (2006). Ablation of ghrelin improves the diabetic but not obese phenotype of ob/ob mice. Cell Metab 3, 379-386.

Szentirmai, E., Kapas, L., Sun, Y., Smith, R.G., and Krueger, J.M. (2009). The preproghrelin gene is required for the normal integration of thermoregulation and sleep in mice. Proc Natl Acad Sci USA 106, 14069-14074.

Tack, J., Depoortere, I., Bisschops, R., Delporte, C., Coulie, B., Meulemans, A., Janssens, J., and Peeters, T. (2006). Influence of ghrelin on interdigestive gastrointestinal motility in humans. Gut 55, 327-333.

Takada, R., Satomi, Y., Kurata, T., Ueno, N., Norioka, S., Kondoh, H., Takao, T., and Takada, S. (2006). Monounsaturated fatty acid modification of Wnt protein: its role in Wnt secretion. Dev Cell 11, 791-801.

Taylor, M.S., Ruch, T.R., Hsiao, P.Y., Hwang, Y., Zhang, P., Dai, L., Huang, C.R., Berndsen, C.E., Kim, M.S., Pandey, A., Wolberger, C., Marmorstein, R., Machamer, C., Boeke, J.D., and Cole, P.A. (2013). Architectural organization of the metabolic regulatory enzyme ghrelin O-acyltransferase. J Biol Chem 288, 32211-32228.

Teramae, H., Yoshikawa, T., Inoue, R., Ushida, K., Takebe, K., Nio-Kobayashi, J., and Iwanaga, T. (2010). The cellular expression of SMCT2 and its comparison with other transporters for monocarboxylates in the mouse digestive tract. Biomed Res 31, 239-249.

Teubner, B.J., Garretson, J.T., Hwang, Y., Cole, P.A., and Bartness, T.J. (2013). Inhibition of ghrelin O-acyltransferase attenuates food deprivation-induced increases in ingestive behavior. Horm Behav 63, $667-673$

Theander-Carrillo, C., Wiedmer, P., Cettour-Rose, P., Nogueiras, R., Perez-Tilve, D., Pfluger, P., Castaneda, T.R., Muzzin, P., Schurmann, A., Szanto, I., Tschop, M.H., and Rohner-Jeanrenaud, F. (2006). Ghrelin action in the brain controls adipocyte metabolism. J Clin Invest 116, 1983-1993.

Trudel, L., Tomasetto, C., Rio, M.C., Bouin, M., Plourde, V., Eberling, P., and Poitras, P. (2002). Ghrelin/motilin-related peptide is a potent prokinetic to reverse gastric postoperative ileus in rat. Am J Physiol Gastrointest Liver Physiol 282, G948-952.

Tschop, M., Smiley, D.L., and Heiman, M.L. (2000). Ghrelin induces adiposity in rodents. Nature 407, 908-913.

Tsubone, T., Masaki, T., Katsuragi, I., Tanaka, K., Kakuma, T., and Yoshimatsu, H. (2005). Ghrelin regulates adiposity in white adipose tissue and UCP1 mRNA expression in brown adipose tissue in mice. Regul. Peptides 130, 97-103.

Vaughan, A.M., and Oram, J.F. (2005). ABCG1 redistributes cell cholesterol to domains removable by high density lipoprotein but not by lipid-depleted apolipoproteins. J Biol Chem 280, 30150-30157.

Wiedmer, P., Strasser, F., Horvath, T.L., Blum, D., Dimarchi, R., Lutz, T., 
Schurmann, A., Joost, H.G., Tschop, M.H., and Tong, J. (2011). Ghrelin-induced hypothermia: a physiological basis but no clinical risk. Physiol Behav 105, 43-51.

Xu, G., Li, Y., An, W., Li, S., Guan, Y., Wang, N., Tang, C., Wang, X., Zhu, Y., Li, X., Mulholland, M.W., and Zhang, W. (2009). Gastric mammalian target of rapamycin signaling regulates ghrelin production and food intake. Endocrinology 150, 3637-3644.

Xu, G., Wang, Z., Li, Y., Li, Z., Tang, H., Zhao, J., Xiang, X., Ding, L., Ma, L., Yuan, F., Fei, J., Wang, W., Wang, N., Guan, Y., Tang, C., Mulholland, M., and Zhang, W. (2012). Ghrelin contributes to derangements of glucose metabolism induced by rapamycin in mice. Diabetologia 55, 1813-1823.

Yang, J., Brown, M.S., Liang, G., Grishin, N.V., and Goldstein, J.L. (2008a). Identification of the acyltransferase that octanoylates ghrelin, an appetite-stimulating peptide hormone. Cell 132, 387-396.
Yang, J., Zhao, T.J., Goldstein, J.L., and Brown, M.S. (2008b). Inhibition of ghrelin O-acyltransferase (GOAT) by octanoylated pentapeptides. Proc Natl Acad Sci USA 105, 10750-10755.

Zhao, T.J., Liang, G., Li, R.L., Xie, X., Sleeman, M.W., Murphy, A.J., Valenzuela, D.M., Yancopoulos, G.D., Goldstein, J.L., and Brown, M.S. (2010). Ghrelin O-acyltransferase (GOAT) is essential for growth hormone-mediated survival of calorie-restricted mice. Proc Natl Acad Sci USA 107, 7467-7472.

Zhu, X., Cao, Y., Voogd, K., and Steiner, D.F. (2006). On the processing of proghrelin to ghrelin. J Biol Chem 281, 38867-38870.

Zigman, J.M., Nakano, Y., Coppari, R., Balthasar, N., Marcus, J.N., Lee, C.E., Jones, J.E., Deysher, A.E., Waxman, A.R., White, R.D., Williams, T.D., Lachey, J.L., Seeley, R.J., Lowell, B.B., and Elmquist, J.K. (2005). Mice lacking ghrelin receptors resist the development of diet-induced obesity. J Clin Invest 115, 3564-3572.

Open Access This article is distributed under the terms of the Creative Commons Attribution License which permits any use, distribution, and reproduction in any medium, provided the original author(s) and source are credited. 